\title{
PID Controller Design for Tito Processes Based on IMC and Smith Predictor Configuration
}

\author{
M Jagjeevanrao, R Kiranmayi
}

\begin{abstract}
This paper describes the design of Proportional-Integral-Derivative (PID) controller for two variable processes where the two variables need to control. Design of controllers for such a process is too difficult than single variable processes because of interrelations between the two variables present in the system. Hence, the design approach should include the interrelations of the variables to achieve better performance of the processes. In addition to this, the time delay of the processes is also considered and Smith Predictor (SP) configuration is used to reduce the delay in the processes. For the resultant reduced time delay processes, an IMC approach is used to design PID controller. The proposed control system improves both the servo (set point tracking) and regulatory (disturbance rejection) performance of the system. The proposed configuration is also validated using a case study. The simulation results are presented and compared with the other similar approaches to show the efficacy of the proposed method.
\end{abstract}

Keywords: Two variable process, time delay, Smith Predictor (SP), single variable processes, IMC based PID, servo and regulatory operation.

\section{INTRODUCTION}

In industry, PID controller is more popularly using for achieving the better set point tracking and minimization of effect of disturbances in the process control applications. This PID controller is implemented in different forms may be in its original form of with some modifications. However, this controller gives best performance if the time delay of the process is less than the time constant of the process transfer function model. When the time delay of the process is significantly more than its time constant, the performance of PID is not up to the expectations. Hence, to overcome this and achieve better controlling it needs some modifications in its implementation [1,2].

Smith Predictor (SP) configuration [3] is most useful in this type of processes where the controller is designed without considering the delay part of the model. With the addition of SP, the servo performance of the process is improved but gives sluggish response for when the time constant of the model is too small $[4,5]$.

The presentation of the SP control procedure is influenced by the precision with which the model speaks to the plant. In view of the assumption that the model utilized

matches exactly the plant elements, the closed loop model is given by

Revised Manuscript Received on July 10, 2019.

M Jagjeevanrao, PG Scholar, Department of EEE., JNTUACEA, Anantapuram, AP, India.

(e-mail: jagajeevanraomonala@gmail.com)

Dr. R Kiranmayi, Professor, Department of EEE., JNTUACEA, Anantapuram, AP, India.

(e-mail: 2kiranmayi0109@gmail.com)

$$
\mathrm{T}(\mathrm{s})=\mathrm{G}_{\mathrm{c}}(\mathrm{s}) \mathrm{G}_{\mathrm{m}}(\mathrm{s}) \mathrm{e}^{-\mathrm{L}_{\mathrm{m}} \mathrm{s}}\left[1+\mathrm{G}_{\mathrm{c}}(\mathrm{s}) \mathrm{G}_{\mathrm{m}}(\mathrm{s})\right]^{-1}
$$

As specified by Eq. (1), the parameters of the essential controller, $\mathrm{G}_{\mathrm{c}}(\mathrm{s})$, which is ordinarily taken as PI or PID, might be resolved utilizing a model without including delay element.

Astrom et al. [6] have utilized a "modified Smith predictor scheme with two degrees of freedom" in which they measured both following of set point and minimization of disturbance impact independently. To improve the presentation of the control system a few alterations have been made in structure of SP arrangement by analysts in the writing.

The control framework structure for multivariable procedures with delay turns out to be progressively troublesome in view of the fact that each yield is influenced by each contribution with various time delays [7]. Subsequently, a transfer function lattice description of the multivariable procedure is favored in these cases. Various methodologies have been projected so as to plan controller for multivariable frameworks with numerous time delays. A few authors proposed directly unadulterated multivariable strategies: decoupling control, multivariable PID controllers, and decentralized controllers. Different creators have stretched out the SP to the multivariable case utilizing a plan comparative or proportionate to that of Fig. 1 where G(s) is the plant, $G_{n}(s)$ is the model of the plant, $G_{0}(s)$ is the quick model of the procedure and $\mathrm{C}(\mathrm{s})$ is the essential controller.

So as to apply SP to multivariable frameworks, two methodologies can be typically found. The first one is in planning a decoupling compensator $\mathrm{D}(\mathrm{s})$ for the actual process $\mathrm{G}(\mathrm{s})$ so as to acquire a diagonal predominant apparent procedure, and after that, applying the SP to this obvious procedure $\mathrm{H}(\mathrm{s})=\mathrm{G}(\mathrm{s}) \cdot \mathrm{D}(\mathrm{s})$ (Fig. 2). At that point, the SP configuration can be completed as of that of SISO case. The subsequent one and increasingly basic applies at the same time multivariable control and SP utilizing the plan of Fig. 1 .

Since Internal Model Control (IMC) is having the good deal between the performance and robustness, it is used for tuning of PID controller. The objective of using this is to enhance the performance for both servo and regulatory 


\section{PID CONTROLLER DESIGN FOR TITO PROCESSES BASED ON IMC AND SMITH PREDICTOR CONFIGURATION}

operations.

In this paper, an IMC PID controller in an SP setup is proposed for planning the controller for two variable (TITO) processes. At first, the interaction between the parameters is estimated and matching of input and output variables are distinguished. At that point, each loop pair of input/output is constrained by PID control calculation. The PID controller is structured utilizing IMC idea. Further, the simplified form of the PID controller is acquired by the guess of frequency response. The simulation results of two variable procedures show the adequacy of the anticipated strategy.

The paper is organized as structure of proposed control scheme is explained in section II, IMC representation in SP configuration in section III, Simulation studies in Section IV and finally conclusions are presented.

\section{STRUCTURE OF PROPOSED CONTROL SCHEME}

A schematic representation of basic SP and modified IMC control configuration is shown are Fig. 1 and Fig. 2 respectively. This scheme is extended for controlling the TITO processes to attain the enhanced performance by reducing the time delay in the processes. In Fig. $1, \mathrm{G}_{\mathrm{c}}(\mathrm{s})$ is controller, $G(s)$ is process model, $G_{m}(s)$ is delay free model, and ' $L$ ' represents the time delay of the process. Similarly in Fig. 2, $\mathrm{G}_{\text {imc }}(\mathrm{s})$ is represents the controller designed using IMC principle.

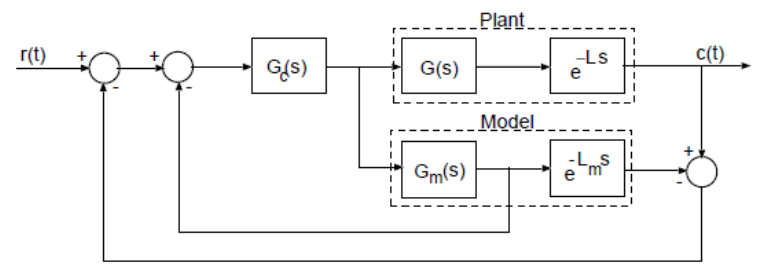

Fig. 1: Basic Structure of SP

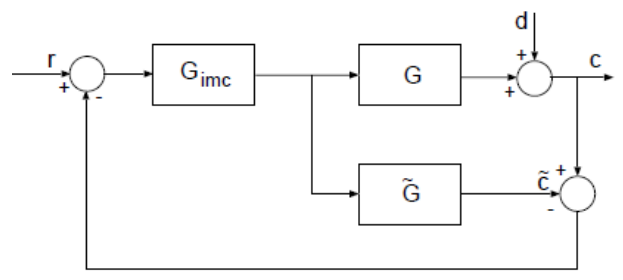

Fig. 2: IMC control system

The most basic representation of the transfer function matrix of the $2 \times 2$ process is:

$$
\mathrm{G}(\mathrm{s})=\left[\begin{array}{ll}
\mathrm{g}_{\mathrm{p}_{11}}(\mathrm{~s}) & \mathrm{g}_{\mathrm{p} 12}(\mathrm{~s}) \\
\mathrm{g}_{\mathrm{p}_{21}}(\mathrm{~s}) & \mathrm{g}_{\mathrm{p}_{22}}(\mathrm{~s})
\end{array}\right]
$$

Where, the process $\mathrm{g}_{\mathrm{pij}}(\mathrm{s})$ is assumed as first order process with delay time (FOPDT), i.e.,

$$
\mathrm{g}_{\text {pij }}(\mathrm{s})=\frac{\mathrm{K}}{\tau \mathrm{s}+1} \mathrm{e}^{-\theta \mathrm{s}}
$$

Then, the corresponding structure of decentralized controller is of the form,

$$
\mathrm{G}_{\mathrm{c}}(\mathrm{s})=\left[\begin{array}{cc}
\mathrm{g}_{\mathrm{c} 11}(\mathrm{~s}) & \cdot \\
\cdot & \mathrm{g}_{\mathrm{c} 22}(\mathrm{~s})
\end{array}\right]
$$

The structure of decentralized control for TITO processes using IMC and SP configuration is shown in Fig. 3. In which $\mathrm{G}(\mathrm{s})$ is interactive two variable processes as given in Eqn. (2).

While the controller is designed for two variable processes, it is important to know which output is controlled by which input. This is determined by measuring the interaction among the process variables. The popular approach to measure the interaction is Relative Gain Array (RGA). But due to limitations in RGA method, most of the researchers used it in connection with the NI index. Recently, RGA-RNGA-NI method [8] is used by various researchers to identify the perfect stable control configuration.

The expressions for calculating the interaction using $\operatorname{RGA}(\Lambda)-\mathrm{RNGA}(\phi)-\mathrm{NI}$ are:

$$
\begin{gathered}
\Lambda=\left[\lambda_{i j}\right]_{2 \times 2}=G_{p}(0) \otimes G_{p}(0)^{-T} \\
\phi=\left[\phi_{i j}\right]_{2 \times 2}=K_{N} \otimes K_{N}^{-T} \\
\mathrm{~K}_{\mathrm{N}, \mathrm{ij}}=\frac{\mathrm{g}_{\mathrm{ij}}(0)}{\tau_{\mathrm{ar}, \mathrm{ij}}}=\frac{\mathrm{k}_{\mathrm{ij}}}{\tau_{\mathrm{ij}}+\theta_{\mathrm{ij}}} \\
N(G)=\frac{\left|G_{p}(0)\right|}{\pi g_{p, i j}} \quad i, j=1,2
\end{gathered}
$$

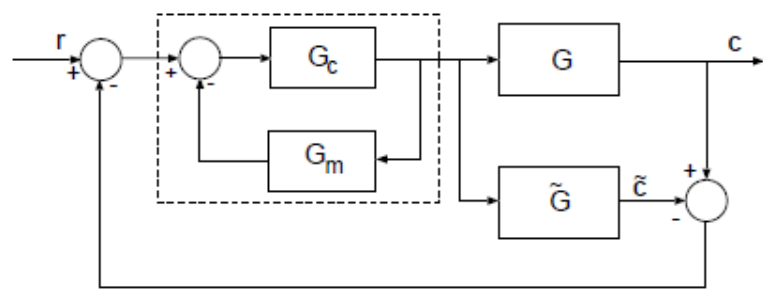

Fig. 3: Closed loop process using IMC in SP configuration

\section{IMC REPRESENTATION OF A SMITH PREDICTOR}

The closed loop transfer function of an SP, assuming an exact matching, is given as:

$$
\mathrm{T}_{\text {Smith }}(\mathrm{s})=\frac{\mathrm{G}_{\mathrm{c}}(\mathrm{s}) \mathrm{G}_{\mathrm{m}}(\mathrm{s}) \mathrm{e}^{-\mathrm{1}_{\mathrm{m}} \mathrm{s}}}{1+\mathrm{G}_{\mathrm{c}}(\mathrm{s}) \mathrm{G}_{\mathrm{m}}(\mathrm{s})}
$$

The IMC transfer function in closed loop, assuming an exact matching and $d=0$, is given as:

$$
\mathrm{T}_{\mathrm{IMC}}(\mathrm{s})=\mathrm{G}_{\mathrm{IMC}}(\mathrm{s}) \mathrm{G}(\mathrm{s})
$$

This can be rewrite as:

$$
\mathrm{T}_{\mathrm{IMC}}(\mathrm{s})=\mathrm{G}_{\mathrm{IMC}}(\mathrm{s}) \mathrm{G}(\mathrm{s}) \mathrm{e}^{-\mathrm{l}_{\mathrm{m}} \mathrm{s}}
$$

where, $G_{m}(s)$ is a process model without time delay. To have a similar response to the two arrangements, it is clear to show, by observing at Eqns. (10) and (11), that the IMC controller, $\mathrm{G}_{\mathrm{IMC}}(\mathrm{s})$, is identified with that controller, $\mathrm{G}_{\mathrm{c}}(\mathrm{s})$, through the change is: 


$$
\mathrm{G}_{\mathrm{IMC}}(\mathrm{s})=\frac{\mathrm{G}_{\mathrm{c}}(\mathrm{s})}{1+\mathrm{G}_{\mathrm{c}}(\mathrm{s}) \mathrm{G}_{\mathrm{m}}(\mathrm{s})}
$$

Along these lines, from Eq. (12), a Smith indicator structure can be put into the IMC structure has appeared in Fig. 3.

To determine the tuning parameters for the controller $\mathrm{G}_{\mathrm{c}}(\mathrm{s})$ in Fig. 3, initially, a FOPDT model is considered. So as to get the IMC controller, the procedure model, ${ }^{\sim} \mathrm{G}=$ $\mathrm{K}_{\mathrm{m}} \mathrm{e}^{-\mathrm{L}}{ }_{\mathrm{m}}^{\mathrm{s}} /\left(\mathrm{T}_{\mathrm{m}} \mathrm{s}+1\right)$, must be figured as in Eqn. (13). The Taylor series expansion is utilized for the estimation of time-delay, at that point the accompanying conditions are determined.

$$
\tilde{\mathrm{G}}(\mathrm{s})=\tilde{\mathrm{G}}_{+}(\mathrm{s}) \tilde{\mathrm{G}}_{-}(\mathrm{s})
$$

The basic IMC principle is,

$$
\mathrm{G}_{\mathrm{IMC}}(\mathrm{s})=\tilde{\mathrm{G}}_{-}^{-1}(\mathrm{~s}) \mathrm{F}(\mathrm{s})
$$

Where, $F(s)=\frac{1}{(\lambda s+1)^{n}}$

After the substitution from Eqn. (1), it becomes,

$$
\begin{aligned}
& \mathrm{T}_{\mathrm{r}}(\mathrm{s})=\frac{\mathrm{G}(\mathrm{s}) \mathrm{F}(\mathrm{s})}{\tilde{\mathrm{G}}_{-}(\mathrm{s})+[\mathrm{G}(\mathrm{s})-\tilde{\mathrm{G}}(\mathrm{s})] \mathrm{F}(\mathrm{s})} \\
& \mathrm{T}_{\mathrm{d}}(\mathrm{s})=\frac{\tilde{\mathrm{G}}_{-}(\mathrm{s})[1-\mathrm{F}(\mathrm{s})]}{\tilde{\mathrm{G}}_{-}(\mathrm{s})+[\mathrm{G}(\mathrm{s})-\tilde{\mathrm{G}}(\mathrm{s})] \mathrm{F}(\mathrm{s})} \\
& \tilde{\mathrm{G}}_{+}(\mathrm{s})=(1-\mathrm{Ls}) \\
& \tilde{\mathrm{G}}_{-}(\mathrm{s})=\frac{\mathrm{K}_{\mathrm{m}}}{\mathrm{T}_{\mathrm{m}} \mathrm{s}+1}
\end{aligned}
$$

From Eqn. (14), IMC controller is obtained by assuming that a filter with $n=1$, as:

$$
\mathrm{G}_{\mathrm{IMC}}(\mathrm{s})=\frac{\mathrm{T}_{\mathrm{m}} \mathrm{s}+1}{\mathrm{~K}_{\mathrm{m}}(\lambda \mathrm{s}+1)}
$$

Eq. (19) demonstrates that, when the parameters of the model, $\mathrm{K}_{\mathrm{m}}$ and $\mathrm{T}_{\mathrm{m}}$, are known, at that point just the filter parameter, $\lambda$, remains to be chosen. The exemplary controller, $\mathrm{G}_{\mathrm{c}}(\mathrm{s})$ would then be able to be gotten utilizing Eqn. (12) to give,

$$
\mathrm{G}_{\mathrm{C}}(\mathrm{s})=\frac{\mathrm{T}_{\mathrm{m}} \mathrm{s}+1}{\mathrm{~K}_{\mathrm{m}} \lambda \mathrm{s}}
$$

Eqn. (20) can be rewritten as a basic ideal form of PI controller, which results the controller parameters as follows.

$$
\begin{aligned}
\mathrm{K}_{\mathrm{p}} & =\frac{\mathrm{T}_{\mathrm{m}}}{\mathrm{K}_{\mathrm{m}} \lambda} \\
\mathrm{T}_{\mathrm{i}} & =\mathrm{T}_{\mathrm{m}}
\end{aligned}
$$

The main unknown in the last two conditions is the time constant of filter, $\lambda$, since it is accepted that the plant mathematical model is acquired utilizing the relay technique. Along these lines, in the event that an appropriate estimation of ' $\lambda$ ' is accomplished, at that point, the design strategy will be finished.

From Fig.1, the output $C(s)$, is obtained as:

$$
\frac{\mathrm{C}(\mathrm{s})}{\mathrm{R}(\mathrm{s})}=\frac{\mathrm{G}_{\mathrm{c}} \mathrm{G}_{\mathrm{m}}}{1+\mathrm{G}_{\mathrm{c}} \mathrm{G}_{\mathrm{m}}} \mathrm{e}^{-\mathrm{Ls}}
$$

Expecting an exact matching between the procedure (plant) and the model, Substituting the best possible qualities for $\mathrm{G}_{\mathrm{c}}(\mathrm{s})$ given by Eqn. (20) and $\mathrm{G}_{\mathrm{m}}(\mathrm{s})=\mathrm{K}_{\mathrm{m}} /\left(\mathrm{T}_{\mathrm{m}} \mathrm{s}+1\right)$ into Eqn. (23) and accepting a unit step change into the framework gives,

$$
C(s)=\frac{1}{s(\lambda s+1)} e-L_{m} s
$$

Using a first-order Taylor series expansion it can be written as:

$$
c(t)=1-\left(1+\frac{L_{m}}{\lambda}\right) e^{-t / \lambda}
$$

By applying the derivative of $\operatorname{ISE}=\frac{\left(\lambda+\mathrm{L}_{\mathrm{m}}\right)^{2}}{2 \lambda}$ with respect to $\lambda$, it provides $\lambda=L_{\mathrm{m}}$. At last, the parameters of PI controller are:

$$
\begin{aligned}
\mathrm{K}_{\mathrm{p}} & =\frac{\mathrm{T}_{\mathrm{m}}}{\mathrm{K}_{\mathrm{m}} \mathrm{L}_{\mathrm{m}}} \\
\mathrm{T}_{\mathrm{i}} & =\mathrm{T}_{\mathrm{m}}
\end{aligned}
$$

Processes with two variables are also very common. This is why a similar result to that for the FOPDT transfer function is also applicable for the two variable processes. Following the same procedure as for the FOPDT transfer function, it can easily be shown that the classical controller can now be implemented for two variable processes.

The entire process of designing the controller for TITO processes includes the following steps:

i) When the controller needs to design a two-variable process, first the interaction between the processes has to measure. In this paper, the interaction between the process variables is measured using RGA-RNGA-NI configuration rules.

ii) Based on the outcome of RGA-RNGA-NI, the pairing of input and output variables are formed and the corresponding process model is used to design the controller.

iii) In the performance of two variable processes, time delay plays an important role, it is considered in this paper and smith predictor configuration is used to compensate the time delay.

iv) Finally, the controller is designed for the process model using the IMC principle and performance of the approach is evaluated.

The performance of the projected method is analyzed using the time integral performance indexes i.e., Integral of Absolute Error (IAE), Integral of the Square Error (ISE). Minimization of IAE and ISE is considered as the objective of present paper.

The time integral performance criteria are expressed as:

$$
\begin{aligned}
& \text { IAE }=\int_{0}^{\infty}\left(\left|e_{1}(t)\right|+\left|e_{2}(t)\right|\right) d t \\
& \text { ISE }=\int_{0}^{\infty}\left(e_{1}^{2}(t)+e_{2}^{2}(t)\right) d t \\
& \text { ITAE }=\int_{0}^{\infty} t\left(\left|e_{1}(t)\right|+\left|e_{2}(t)\right|\right) d t
\end{aligned}
$$




\section{PID CONTROLLER DESIGN FOR TITO PROCESSES BASED ON IMC AND SMITH PREDICTOR CONFIGURATION}

\section{RESULTS \& DISCUSSIONS}

\section{Process:}

Consider the Wood and berry (WB) column which is a two variable process. The mathematical model of a process is given in Eqn. (27).

$$
G(s)=\left[\begin{array}{cc}
\frac{12.8 \mathrm{e}^{-3 \mathrm{~s}}}{16.7 \mathrm{~s}+1} & \frac{-18.9 \mathrm{e}^{-3 \mathrm{~s}}}{21 \mathrm{~s}+1} \\
\frac{6.6 \mathrm{e}^{-7 \mathrm{~s}}}{10.9 \mathrm{~s}+1} & \frac{-19.4 \mathrm{e}^{-3 \mathrm{~s}}}{14.4 \mathrm{~s}+1}
\end{array}\right]
$$

Since it is $2 \times 2$ process, the two decentralized controllers are required. The interaction obtained using relative gain array is:

$$
\lambda=\left[\begin{array}{cc}
2.0094 & -1.0094 \\
-1.0094 & 2.0094
\end{array}\right]
$$

Relative Normalize Gain Array (RNGA) is:

$$
\phi=\left[\begin{array}{cc}
1.0806 & -0.0806 \\
-0.0806 & 1.0806
\end{array}\right]
$$

Based on the results of RGA and RNGA, the pair of $\mathrm{u}_{1}-\mathrm{y}_{1}, \mathrm{u}_{2}-\mathrm{y}_{2}$ is having strong interaction. Hence the controller is designed for these two pairs.

Thus, the diagonal process transfer function models are considered for intend of controller are

$$
\begin{gathered}
g_{p, 11}(s)=\frac{12.8 e^{-s}}{16.7 s+1} \\
g_{p, 22}(s)=\frac{-19.4 e^{-3 s}}{14.4 s+1}
\end{gathered}
$$

Based on these two process models, the diagonal decentralised controllers are intended individually $\left(g_{\mathrm{c} 11}\right.$ and $\left.g_{c 22}\right)$ using IMC tuning method. The controllers have been designed without the compensator (time delay is not considered in controller design) and with compensator. The controller's values obtained for these two approaches are used in simulation and results have been shown in Fig. 4 and Fig. 5. The first output is shown in Fig. 4. Similarly, the second output is shown in Fig. 5.

The response of time delay compensated method is having less oscillations and settled to a reference as quickly as possible as compared to the other method where the time delay not considered in designing of controller.

The performance of the two control methods are measured in terms of IAE, ISE and ITAE. These are listed in Table.1.

Table I:

Performance indices of two variable process WB Column.

\begin{tabular}{|c|c|c|c|c|}
\hline $\begin{array}{c}\text { Control } \\
\text { Method }\end{array}$ & Input(u)-output(y) & IAE & ISE & ITAE \\
\hline $\begin{array}{c}\text { Proposed } \\
\text { (IMC PID in } \\
\text { SP) }\end{array}$ & $\mathrm{u}_{1}-\mathrm{y}_{1}$ & 4.185 & 2.13 & 33.38 \\
& $\mathrm{u}_{2}-\mathrm{y}_{2}$ & 9.316 & 5.868 & 825 \\
& & & & \\
\hline IMC PI & $\mathrm{u}_{1}-\mathrm{y}_{1}$ & 7.247 & 2.44 & 340 \\
& $\mathrm{u}_{2}-\mathrm{y}_{2}$ & 14.83 & 8.418 & 873.4 \\
\hline
\end{tabular}

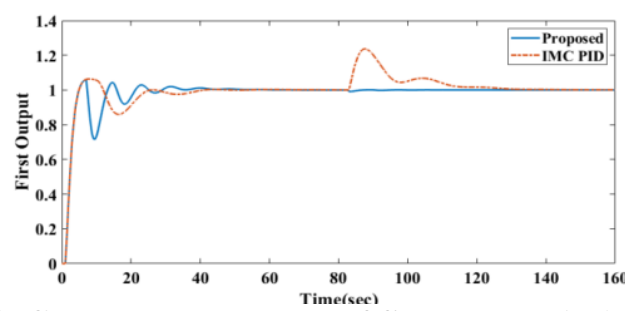

Fig. 4: Closed loop response of first output $\left(\mathrm{Y}_{1}\right)$ of WB column

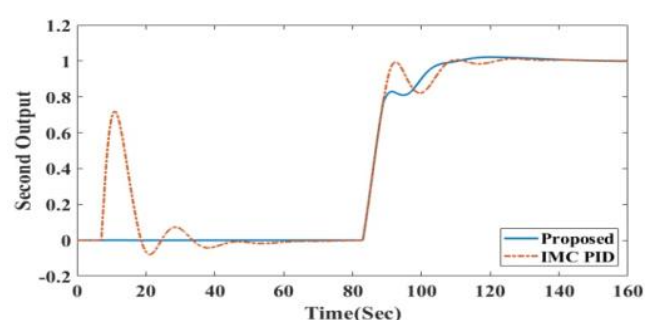

Fig. 5: Closed loop response of second output $\left(\mathrm{Y}_{2}\right)$ of WB column

\section{CONCLUSIONS}

In this paper, a decentralized controller with IMC is designed in SP configuration for two variable processes. The interaction amid the variables is considered in design of controller. The pair of variables has been identified using the concepts of RNGA-RGA-NI approach. The model for corresponding pair is derived and controller is intended for the same. The time delay of the process model was compensated by SP configuration. The resultant control system is gives the improved performance and robustness. The proposed scheme performance is compared with basic IMC method. From these two performances, it is observed that the proposed method gives better improvement in terms of IAE and ISE.

\section{REFERENCES}

1. Meyer, C., D. E. Seborg, and R. K. Wood. "A comparison of the Smith predictor and conventional feedback control." Chemical Engineering Science 31.9 (1976): 775-778.

2. Hagglund, Tore. "A predictive PI controller for processes with long dead times." IEEE Control Systems Magazine 12.1 (1992): 57-60.

3. Smith, Otto JM. "A controller to overcome dead time." ISA J. 6 (1959): 28-33.

4. Anwar, Md Nishat, Somnath Pan, and Ashraf Raza. "PID Controller Tuning in Smith Predictor Configuration for Stable Processes with Large Time Delay Using IMC Scheme." Innovations in Soft Computing and Information Technology. Springer, Singapore, 2019. 249-260.

5. Watanabe, Keiji, and Masami Ito. "A process-model control for linear systems with delay." IEEE Transactions on Automatic control 26.6 (1981): 1261-1269.

6. Astrom, Karl J., Chang C. Hang, and B. C. Lim. "A new Smith predictor for controlling a process with an integrator and long dead-time." IEEE transactions on Automatic Control 39.2 (1994): 343-345.

7. Naik, R. Hanuma, DV Ashok Kumar, and K. S. R. Anjaneyulu. "Loop Interaction and It's Influence in Multivariable Process Control." Emerging Trends in Electrical, Communications and Information Technologies. Springer, Singapore, 2017. 361-368.

8. V. Vijay-Kumar, V. S. R. Rao, and M. Chidambaram, "Centralized PI controllers for interacting multivariable processesby synthesis method," ISA Trans., vol. 51, pp. 400-409, 2012. 